\title{
Pontocerebellar hypoplasia type 9
}

INSERM

\section{Source}

INSERM. (1999). Orphanet: an online rare disease and orphan drug data base.

Pontocerebellar hypoplasia type 9. ORPHA:369920

Pontocerebellar hypoplasia type 9 is a rare, genetic, subtype of non-syndromic pontocerebellar hypoplasia characterized by progressive cerebellum and brainstem atrophy, corpus callosum hypo-/aplasia and progressive post-natal microcephaly. Patients typically present profound global developmental delay, spastic tetraparesis, seizures, cortical visual impairment and, on neuroimaging, abnormal brain morphology that includes pontocerebellar hypoplasia, "figure of 8" midbrain appearance, and, more variably, interhemispheric cysts, ventriculomeg aly and cerebral dysmyelination. 